\title{
The ethical and legal status of neurosurgical guidelines: the neurosurgeon's golden fleece or Achilles' heel?
}

\author{
${ }^{*}$ Ishaan Ashwini Tewarie, BSc, ${ }^{1-3}$ Alexander F. C. Hulsbergen, BSc, ${ }^{1-3}$ Victor Volovici, MD, PhD, ${ }^{4,5}$ \\ and Marike L. D. Broekman, MD, PhD, LLM'-3 \\ ${ }^{1}$ Computational Neurosciences Outcomes Center, Department of Neurosurgery, Brigham and Women's Hospital, Harvard \\ Medical School, Boston, Massachusetts; ${ }^{2}$ Department of Neurosurgery, Haaglanden Medical Center, The Hague; ${ }^{3}$ Department of \\ Neurosurgery, Leiden Medical Center, Leiden; ${ }^{4}$ Department of Neurosurgery, Erasmus Medical Center, Rotterdam; and ${ }^{5}$ Center \\ for Medical Decision Making, Department of Public Health, Erasmus Medical Center, Rotterdam, The Netherlands
}

\begin{abstract}
Neurosurgical guidelines are fundamental for evidence-based practice and have considerably increased both in number and content over the last decades. Yet, guidelines in neurosurgery are not without limitations, as they are overwhelmingly based on low-level evidence. Such recommendations have in the past been occasionally overturned by welldesigned randomized controlled trials (RCTs), demonstrating the volatility of poorly underpinned evidence. Furthermore, even RCTs in surgery come with several limitations; most notably, interventions are often insufficiently standardized and assume a homogeneous patient population, which is not always applicable to neurosurgery. Lastly, guidelines are often outdated by the time they are published and smaller fields such as neurosurgery may lack a sufficient workforce to provide regular updates. These limitations raise the question of whether it is ethical to use low-level evidence for guideline recommendations, and if so, how strictly guidelines should be adhered to from an ethical and legal perspective. This article aims to offer a critical approach to the ethical and legal status of guidelines in neurosurgery. To this aim, the authors discuss: 1) the current state of neurosurgical guidelines and the evidence they are based on; 2) the degree of implementation of these guidelines; 3) the legal status of guidelines in medical disciplinary cases; and 4) the ethical balance between confident and critical use of guidelines. Ultimately, guidelines are neither laws that should always be followed nor purely academic efforts with little practical use. Every patient is unique, and tailored treatment defined by the surgeon will ensure optimal care; guidelines play an important role in creating a solid base that can be adhered to or deviated from, depending on the situation. From a research perspective, it is inevitable to rely on weaker evidence initially in order to generate more robust evidence later, and clinician-researchers have an ethical duty to contribute to generating and improving neurosurgical guidelines.
\end{abstract}

https://thejns.org/doi/abs/10.3171/2020.8.FOCUS20597

KEYWORDS clinical practice guidelines; evidence-based medicine; ethics; medicolegal environment; malpractice

$\mathrm{P}$ RACTICE guidelines are a cornerstone of modern evidence-based neurosurgery. Having considerably increased in number over the last few decades, 1,2 these guidelines aid individual physicians by summarizing available evidence and formulating recommendations. Moreover, guidelines can help reduce inappropriate practice variation when they are based on strong evidence.

The idea of guidelines is older than modern medicine. In the 4th century BC, Plato pursued a thought experiment in which a physician can only make decisions by partaking in panels composed of both clinicians and nonclinicians, ${ }^{3}$ creating a shift in autonomy from the individual physician to a public realm in which clinical decision-making is continuously scrutinized. ${ }^{4}$ Plato recognized the potential of such a situation, but at the same time viewed it as a sullied form of medical practice. Specifically, he argued that guidelines assume homogeneous conditions for every patient, and therefore do not serve the individual patient. ${ }^{4}$ At present, guidelines do not aim to strip clinicians of their autonomy, but similar concerns expressed by Plato still exist among healthcare professionals.

This paper aims to offer a critical approach to the ethical and legal status of clinical practice guidelines in neurosurgery by discussing: 1) the current state of neurosurgical guidelines and the evidence they are based on; 2) the degree of implementation of these guidelines; 3 ) the legal

ABBREVIATIONS IONM = intraoperative neuromonitoring; RCT = randomized controlled trial; $\mathrm{TBI}=$ traumatic brain injury.

SUBMITTED June 30, 2020. ACCEPTED August 24, 2020.

INCLUDE WHEN CITING DOI: 10.3171/2020.8.FOCUS20597.

* I.A.T. and A.F.C.H. contributed equally to this work. 
status of guidelines in medical disciplinary cases; and 4) the ethical balance between confident and critical use of guidelines.

\section{The Current State of Evidence in Neurosurgical Guidelines}

Guidelines are based on evidence derived from research. Moreover, guidelines are ideally accompanied by a critical appraisal, which reflects a combination of clinical experience, patient preference, and a methodological assessment of existing evidence. ${ }^{5}$ The American Association of Neurological Surgeons and the Congress of Neurological Surgeons recognize three classes of evidence: 1) class $\mathrm{I}=$ well-designed randomized controlled trials (RCTs) and meta-analyses of RCTs; 2 ) class II = well-designed cohorts, case-control studies, or time series comparisons; and 3) class III $=$ other studies, expert opinions, and consensusbased recommendations. ${ }^{6}$

Neurosurgical evidence has been continuously improving over the last decades. ${ }^{7}$ Specifically, for example, from 2011-2015 a total of 191 RCTs were identified in the field of neurotrauma alone. ${ }^{8}$ In addition, the number of neurosurgical guidelines is also increasing: in the past decade, a median of 21 (range 10-53) neurosurgical guidelines per year were published in the US (Fig. 1).

However, neurosurgical guidelines are not without limitations. First, only approximately $9 \%$ of evidence used in neurosurgical clinical practice guidelines is class I evidence. ${ }^{9}$ Yet, $24 \%$ of neurosurgical clinical practice guidelines are regarded as level 1 recommendations, i.e., generally accepted principle for patient management, which reflects a high degree of clinical certainty. ${ }^{9}$ This illustrates an interesting discrepancy in which confidence in current evidence might be overstated. Second, even high-level evidence has its limitations. RCTs in surgery suffer from limitations including: 1) small sample sizes; 2) variability in surgical technique, surgeon experience, and learning curve; 3 ) the subjectivity of some indications for surgery based on surgeons' and patients' preferences, which complicates inclusion criteria; and 4) so-called "heterogeneity of treatment effect," i.e., RCTs measure average treatment effect over a population while disregarding the characteristics of the individual patient. ${ }^{10-13}$ Moreover, class I evidence is still subject to interpretation due to differences in culture ${ }^{14}$ politics, ${ }^{15}$ and conflicts of interest. ${ }^{16}$ Third, most guidelines include out-of-date literature by the time they are published, ${ }^{17}$ which is especially true for lower-level recommendations. ${ }^{18}$ In a relatively small, demanding field such as neurosurgery, there is often too little of a workforce to update guidelines continuously.

Even when keeping the limitations of RCTs in surgery in mind, the abundance of low-level evidence in neurosurgical guidelines should engender caution, as clinical recommendations based on low-level evidence can be reversed; high-quality RCTs can overturn previous recommendations based on observational data and expert opinions. Prasad and Cifu coined the term "medical reversal" to describe this process of overturning "false" consensus. ${ }^{19}$ A medical reversal could arguably be used as a reason for nonadherence to neurosurgical guidelines. In neurology/

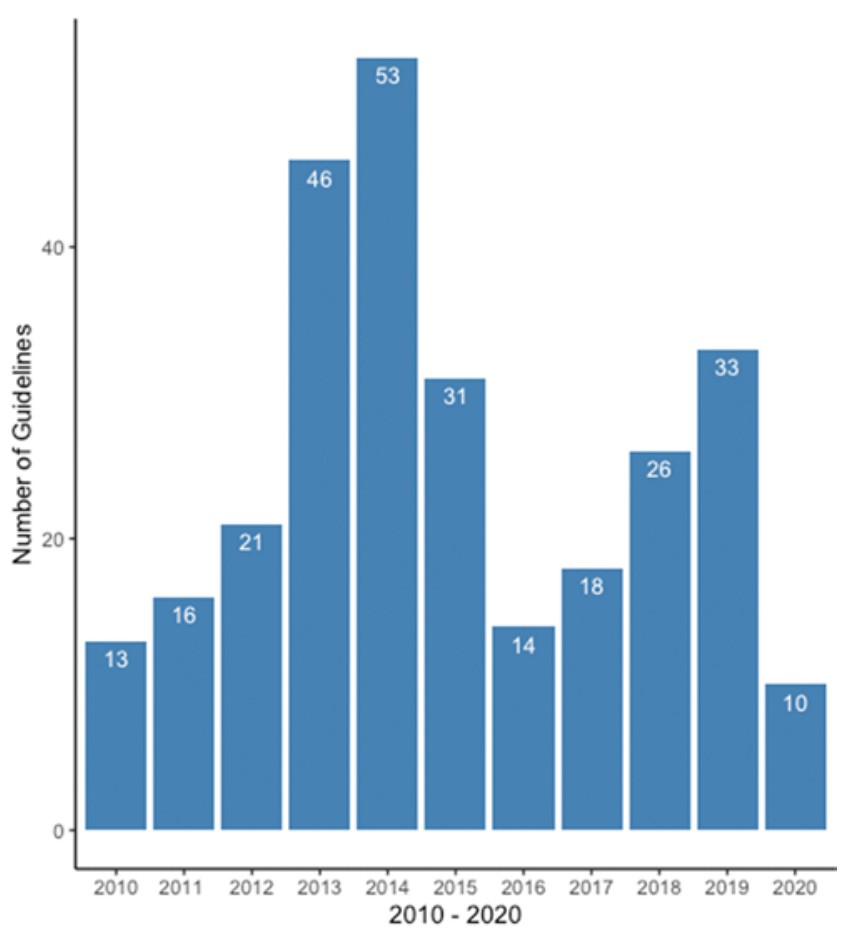

FIG. 1. Number of neurosurgical guidelines published in the US per year.

neurosurgery, $6 \%$ of trials published in the three leading medical journals (The New England Journal of Medicine, The Lancet, and The Journal of the American Medical Association) resulted in a reversal of consensus. ${ }^{20}$ One example is the CRASH (Corticosteroid Randomisation After Significant Head Injury) trial, which demonstrated evidence of harm, i.e., an increased mortality rate in patients receiving dexamethasone in the acute phase of traumatic brain injury (TBI), which was in wide use up to that point. ${ }^{21}$ This example raises the question of how strictly neurosurgeons should adhere to guideline recommendations based on lower classes of evidence.

\section{Adherence to Guidelines}

Adherence to guidelines varies. In neurosurgical practice, a recent Europe-wide survey showed that medical management of severe TBI varied over 65 centers, of which only 38\% reported structural implementation of guidelines daily. Seventeen percent of all participating centers reported no use of guidelines at all, using "every patient is unique" as the main reasoning for this choice. ${ }^{22}$ While this adage is evidently true, it should not undermine the use of guidelines for individual decision-making. To optimize treatment for each patient, we need to establish which intervention is favorable at a patient-population level..$^{23} \mathrm{~A}$ possible solution would be to stratify patients by predicted risk and combine results of RCTs with prediction modeling, thereby conferring more statistical power to the analyses and gaining more insight into the expected results based on preexistent risk..$^{23,24}$ The future of evidence-based medicine may move more toward a risk-based approach and away from "classic" RCTs, which estimate the effect size on a 
population level but possibly suffer from the heterogeneity of treatment effect. ${ }^{23,25}$ More research is needed to improve our understanding of the proper manner in which guideline use can be individualized. ${ }^{23}$

\section{Legal Implications of Guidelines}

In a legal setting, guidelines can protect both patients and physicians. When neurosurgeons use evidence-based meritorious treatment options as defined within guidelines, potential malpractice claims based on adverse outcomes are less likely to be filed, or if they are, less likely to be upheld in court. ${ }^{26}$ Conversely, deviation from a guideline (especially when based on low-level evidence) should not necessarily mean a negative outcome for the defendant in a medical disciplinary case. ${ }^{27}$ One example of a discrepancy between evidence-based neurosurgery and common practice is intraoperative neuromonitoring (IONM). While IONM in spinal tumor surgery is widely used, there is no solid evidence that its use is associated with superior functional outcomes; conversely, IONM has even been associated with a higher rate of subtotal resection. ${ }^{28}$ Despite this, IONM has been used as an argument in medical disciplinary cases by both the plaintiff to advance their allegation of negligence and by the defendant to exculpate liability. ${ }^{29}$

Guideline adherence or deviation can be used as an extra argument in a case. Judges and experts can use guidelines to study the strength of evidence used in the recommendations and take this into account if necessary; the guidelines themselves are not laws, and deviation is not a liable offense in itself. In fact, this may, in certain circumstances, be ethically and legally required.

One example to illustrate this is the case of Chumbler $v$ McClure (505 F.2d 489 [6th Cir. 1974]). In this case, the plaintiff sued Dr. McClure, a neurosurgeon, for side effects he was experiencing from an unstandardized treatment for cerebrovascular disease. Although Dr. McClure was the only one using this therapy in the geographical area, the court ruled that simply deviating from conventional treatment did not make the treatment wrong. Since Chumbler $v$ McClure, deviation from the standard of care does not inherently imply negligence; negligence is not a factor if a "respectable minority" of doctors agree with the unstandardized intervention. ${ }^{30,31}$ Guidelines can help with standardizing and formulating protective measures that will ensure patients' access to high-risk procedures without neurosurgeons having to worry about liability risk. Protective measures will also ensure meritorious "good practice" as the standard of care instead of a conceptual juridical norm. 32

While clinicians might fear increased medicolegal exposure through the proliferation of guidelines, ${ }^{15,33}$ in reality, only $7 \%$ of all medical claims involved guideline use. ${ }^{34}$ To date, the "standard of care" in medical litigation cases is mostly based on what is commonly considered responsible medical practice, and not on guidelines, as the IONM example illustrates. This responsible practice is usually defined by expert witnesses, who may opt to base their advice on guidelines. This highlights an interesting contrast between medical practice and medical disciplinary cases: while expert opinions are considered lower-class evidence in guidelines and everyday practice, they constitute highclass evidence in the courtroom. The justification of using expert opinions in court is that a layperson would not come to the same conclusions as to the expert if given the same underlying material for review. ${ }^{35}$

\section{Critical Versus Confident Use of Guidelines}

Given the limitations of neurosurgical guidelines, the ethical question arises of how much confidence we should bestow on the recommendations issued. Emphasis should be placed on the strength of the evidence and recommendations. ${ }^{36}$ Clinical guidelines need to transparently describe the strengths and limitations of their recommendations while at the same time proposing future research to improve on them. Still, it is inevitable to rely on weaker evidence initially in order to generate stronger evidence later. Eminence is the bedrock of evidence, and eminence- or consensus-based decision-making can be ethically justified if they form a stimulus to generate higher-class evidence, whether they be RCTs or well-conducted observational studies. It is the ethical duty of clinician-researchers to actively fill in the gaps in guidelines and perform research to advance this progressive process.

It is common for neurosurgical guidelines to focus more on what ought not to be done (negative recommendations) instead of what ought to be done (positive recommendations) because current evidence does not support the latter. Although these negative recommendations also form a cornerstone of neurosurgical decision-making, more positive recommendations might decrease practice variation and encourage future research. The damage of such practice variation versus damage done by recommending a suboptimal treatment should carefully be weighed per intervention. This can potentiate ethically responsible guidelines despite the inclusion of lower-level evidence.

\section{Conclusions}

Neurosurgical guidelines are essential for current evidence-based practice. Guidelines are not infallible laws and do not necessarily reflect the standard of care, as they are sometimes underpinned by low-tier evidence. Guidelines should function as an incentive, and not a deterrent, for clinicians to participate in research and to indicate future research priorities.

\section{References}

1. Weisz G, Cambrosio A, Keating P, et al. The emergence of clinical practice guidelines. Milbank Q. 2007;85(4):691-727.

2. Guillaume DJ, Hunt MA, eds. Quality and Safety in Neurosurgery. Academic Press; 2018.

3. Waterfield R, Annas J. Plato: The Statesman. In: Geuss $\mathrm{R}$, Skinner Q. Cambridge Texts in the History of Political Thought. Cambridge University Press; 1995.

4. Sinclair NA. Clinical Guidelines and the Law: Negligence, Discretion and Judgement. Brian Hurwitz, Radcliffe Medical Press; ISBN 185775044 6; Paperback; 152pp; 1998; £19.95. Book review. J Radiother Pract. 2000;1(4):225.

5. Institute of Medicine. Clinical Practice Guidelines We Can Trust. National Academies Press; 2011.

6. Robinson PD, Kalkanis SN, Linskey ME, Santaguida PL. 
Methodology used to develop the AANS/CNS management of brain metastases evidence-based clinical practice parameter guidelines. J Neurooncol. 2010;96(1):11-16.

7. Nuwer MR, Emerson RG, Galloway G, et al. Evidence-based guideline update: intraoperative spinal monitoring with somatosensory and transcranial electrical motor evoked potentials: report of the Therapeutics and Technology Assessment Subcommittee of the American Academy of Neurology and the American Clinical Neurophysiology Society. Neurology. 2012;78(8):585-589.

8. Bragge P, Synnot A, Maas AI, et al. A state-of-the-science overview of randomized controlled trials evaluating acute management of moderate-to-severe traumatic brain injury. $J$ Neurotrauma. 2016;33(16):1461-1478.

9. Ducis K, Florman JE, Rughani AI. Appraisal of the quality of neurosurgery clinical practice guidelines. World Neurosurg. 2016;90:322-339.

10. Fung EK, Loré JM Jr. Randomized controlled trials for evaluating surgical questions. Arch Otolaryngol Head Neck Surg. 2002;128(6):631-634.

11. Stirrat GM, Farrow SC, Farndon J, Dwyer N. The challenge of evaluating surgical procedures. Ann R Coll Surg Engl. 1992;74(2):80-84.

12. Wang H, Barbee D, Xue J, et al. Predicting local recurrence of stereotactic radiosurgery brain metastases using MRI radiomics features. Int Jf Radiat Oncol Biol Phys. 2018;102(3S):E563-E564.

13. Das AK. Randomised clinical trials in surgery: a look at the ethical and practical issues. Indian J Surg. 2011;73(4): 245-250.

14. Schwartz S, Drumheller C. Culture and guidelines: how cultural differences in treatment approach affect interpretation of literature and guideline recommendations. BMJ Quality Safety (Basel). 2013;22(suppl 1):61.

15. Hurwitz B. Legal and political considerations of clinical practice guidelines. BMJ. 1999;318(7184):661-664.

16. Ngo-Metzger Q, Moyer V, Grossman D, et al. Conflicts of interest in clinical guidelines: update of U.S. Preventive Services Task Force policies and procedures. Am J Prev Med. 2018;54(1S1):S70-S80.

17. Clark E, Donovan EF, Schoettker P. From outdated to updated, keeping clinical guidelines valid. Int J Qual Health Care. 2006;18(3):165-166.

18. Volovici V, Steyerberg EW, Cnossen MC, et al. Evolution of evidence and guideline recommendations for the medical management of severe traumatic brain injury. J Neurotrauma. 2019;36(22):3183-3189.

19. Prasad V, Cifu A. Medical reversal: why we must raise the bar before adopting new technologies. Yale J Biol Med. 2011;84(4):471-478.

20. Herrera-Perez D, Haslam A, Crain T, et al. A comprehensive review of randomized clinical trials in three medical journals reveals 396 medical reversals. eLife. 2019;8:e45183.

21. Edwards P, Arango M, Balica L, et al. Final results of MRC CRASH, a randomised placebo-controlled trial of intravenous corticosteroid in adults with head injury-outcomes at 6 months. Lancet. 2005;365(9475):1957-1959.

22. Volovici V, Ercole A, Citerio G, et al. Variation in guideline implementation and adherence regarding severe traumatic brain injury treatment: a CENTER-TBI survey study in Europe. World Neurosurg. 2019;125:e515-e520.

23. Kent DM, Steyerberg E, van Klaveren D. Personalized evidence based medicine: predictive approaches to heterogeneous treatment effects. BMJ. 2018;363:k4245.

24. Collins GS, Reitsma JB, Altman DG, Moons KG. Transparent reporting of a multivariable prediction model for individual prognosis or diagnosis (TRIPOD): the TRIPOD statement. Circulation. 2015;131(2):211-219.
25. Wallach JD, Sullivan PG, Trepanowski JF, et al. Evaluation of evidence of statistical support and corroboration of subgroup claims in randomized clinical trials. JAMA Intern Med. 2017;177(4):554-560.

26. McKhann GM. Clinical Neurosurgery: A Publication of the Congress of Neurological Surgeons. Vol 51. Lippincott Williams \& Wilkins; 2004.

27. Samanta A, Samanta J, Gunn M. Legal considerations of clinical guidelines: Will NICE make a difference? J R Soc Med. 2003;96(3):133-138.

28. Hadley MN, Shank CD, Rozzelle CJ, Walters BC. Guidelines for the use of electrophysiological monitoring for surgery of the human spinal column and spinal cord. Neurosurgery. 2017;81(5):713-732.

29. Brook M, Irle K. Litigating intraoperative neuromonitoring (IOM). Univ Baltimore Law Rev. 2016;45(3):443-561.

30. Scheflin AW. Ethics and hypnosis: unorthodox or innovative therapies and the legal standard of care. In: Matthews WJ, Edgette JH. Current Thinking and Research in Brief Therapy. Vol 2. Routledge; 2013;41-64.

31. Hudson MJ, Moore GP. Defenses to malpractice: what every emergency physician should know. J Emerg Med.2011;41(6): 598-606.

32. Nahed BV, Babu MA, Smith TR, Heary RF. Malpractice liability and defensive medicine: a national survey of neurosurgeons. PLoS One. 2012;7(6):e39237.

33. Newton J, Knight D, Woolhead G. General practitioners and clinical guidelines: a survey of knowledge, use and beliefs. Br J Gen Pract. 1996;46(410):513-517.

34. Hyams AL, Brandenburg JA, Lipsitz SR, et al. Practice guidelines and malpractice litigation: a two-way street. Ann Intern Med. 1995;122(6):450-455.

35. Allgood DBP. Experts may rely on hearsay ... except when they may not. ABA. May 23, 2018. Accessed September 10, 2020. https://www.americanbar.org/groups/litigation/committees/expert-witnesses/articles/2018/spring2018-expertsmay-rely-on-hearsay-except-when-they-may-not/

36. Kreiner DS, Shaffer WO, Baisden JL, et al. An evidencebased clinical guideline for the diagnosis and treatment of degenerative lumbar spinal stenosis (update). Spine $J$. 2013;13(7):734-743.

\section{Disclosures}

The authors report no conflict of interest concerning the materials or methods used in this study or the findings specified in this paper.

\section{Author Contributions}

Conception and design: all authors. Drafting the article: Tewarie, Hulsbergen, Volovici. Critically revising the article: all authors. Reviewed submitted version of manuscript: all authors. Study supervision: Broekman.

\section{Supplemental Information \\ Videos \\ Video Abstract. https://vimeo.com/464978904.}

\section{Correspondence}

Marike L. D. Broekman: Haaglanden Medical Center, The Hague, The Netherlands. m.broekman@haaglandenmc.nl. 